\title{
O PRINCÍPIO DA CAPACIDADE CONTRIBUTIVA NA JURISPRUDÊNCIA DO SUPREMOTRIBUNAL FEDERAL
}

\begin{tabular}{|c|c|}
\hline & $\begin{array}{r}\text { THE ABILITY TO PAY PRINCIPLE IN THE DECISIONS } \\
\text { OF THE BRAZILIAN SUPREME COURT }\end{array}$ \\
\hline 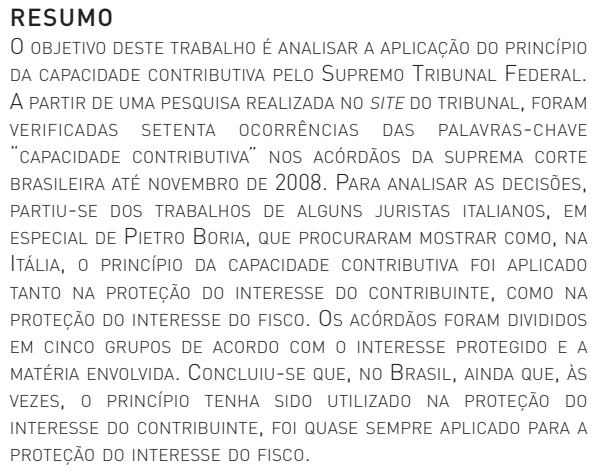 & $\begin{array}{l}\text { ABSTRACT } \\
\text { THE OBJECTIVE OF THIS PAPER IS TO ANALYZE THE } \\
\text { APPLICATION OF THE 'ABILITY TO PAY' PRINCIPLE TO DECISIONS } \\
\text { OF THE BRAZILIAN SUPREME COURT. IN RESEARCH CARRIED } \\
\text { OUT ON THE COURT WEBSITE, THE TERM 'ABILITY TO PAY' } \\
\text { APPEARED } 70 \text { TIMES IN COURT DECISIONS, UNTIL NOVEMBER, } \\
\text { 2008. IN ORDER TO ANALYZE THE DECISIONS, I BEGAN WITH } \\
\text { TEXTS FROM ITALIAN JURISTS, ESPECIALLY PIETRO BORIA, WHO } \\
\text { SOUGHT TO DEMONSTRATE THAT THE ABILITY TO PAY PRINCIPLE } \\
\text { IN ITALY IS APPLIED BOTH IN THE PROTECTION OF TAXPAYER } \\
\text { INTERESTS AS WELL AS THE PROTECTION OF THE STATE. } \\
\text { DECISIONS WERE DIVIDED INTO FIVE GROUPS, ACCORDING } \\
\text { TO THE INTEREST PROTECTED AND THE SUBJECT INVOLVED. } \\
\text { I CONCLUDED THAT, ALTHOUGH SOME TIMES THE PRINCIPLE } \\
\text { HAS BEEN APPLIED IN THE PROTECTION OF THE TAXPAYER } \\
\text { INTERESTS, IT WAS ALMOST ALWAYS APPLIED IN THE } \\
\text { PROTECTION OF THE STATE INTERESTS. }\end{array}$ \\
\hline $\begin{array}{l}\text { PALAVRAS-CHAVE } \\
\text { CAPACIDADE CONTRIBUTIVA; SUPREMO TRIBUNAL FEDERAL; } \\
\text { PROGRESSIVIDADE; IGUALDADE; INTERPRETACĀO }\end{array}$ & $\begin{array}{l}\text { KEYWORDS } \\
\text { ABILITY TO PAY; BRAZILIAN SUPREME COURT; PROGRESSIVITY; } \\
\text { EQUITY; INTERPRETATION. }\end{array}$ \\
\hline
\end{tabular}

\section{INTRODUÇÃO}

O princípio da capacidade contributiva ingressou no ordenamento jurídico brasileiro com a constituição de 1946. Seu artigo 202 dispunha: "Os tributos terão caráter pessoal, sempre que isso for possível, e serão graduados conforme a capacidade econômica do contribuinte".

Esse princípio foi excluído dos textos de 1967/69 e novamente inscrito na constituição de 1988. O parágrafo $1^{\circ}$ do seu artigo 145 dispõe: "Sempre que possível, os 
No mesmo sentido, o RE-ED 209.014/SP, em que uma empresa de seguros sustenta a inconstitucionalidade do $\S 2^{\circ}$ do artigo $3^{\circ}$ da Lei $7.787 / 89$, por ter instituído o adicional de $2,5 \%$ sobre a contribuição para a previdência social indistintamente para bancos comerciais, bancos de investimento, bancos de desenvolvimento, caixas econômicas, sociedades de crédito e também para empresas de seguro privadas.

Argumenta-se que a capacidade contributiva da recorrente, a empresa de seguro independente, de pequeno porte, não pode se equiparar às empresas que se destacam no cenário financeiro nacional e que haveria, em outros setores, centenas de empresas com capacidade contributiva maior que a da recorrente não obrigadas ao pagamento do adicional.

Dois pontos merecem destaque no acórdão do STF. Em primeiro lugar, o STF decidiu que não se aplica o princípio da isonomia, pois há uma grande diferença entre os bancos comerciais e as empresas prestadoras de serviço, etc.

Em segundo lugar, no entanto, a $1^{a}$ turma decidiu, nos termos do voto do relator, ministro Sepúlveda Pertence, que o princípio da capacidade contributiva não se aplica às contribuições sociais que "não são sub-espécies do tributo a que alude o dispositivo" (o artigo $145, \S 1^{\circ}$, dispõe sobre impostos).

Nesse sentido, aponta-se uma divergência no posicionamento dos ministros. Enquanto nos acordãos relativos às taxas, classificados no quar to grupo, decidiu-se que não se aplicaria literalmente o $\S 1^{\circ}$ do artigo 145 , no acórdão supra referido decidiuse justamente o contrário, isto é, foi exatamente sua interpretação literal que impediu, para o ministro Pertence, a aplicação do princípio às contribuições sociais.

\section{CONCLUSÃo}

O objetivo deste trabalho foi analisar a aplicação do princípio da capacidade contributiva pelo Supremo Tribunal Federal.

A partir dos trabalhos da doutrina italiana e, em especial, de Pietro Boria, foi visto como o princípio da capacidade contributiva protege dois interesses distintos: o interesse do contribuinte em não pagar tributos além de sua capacidade contributiva e o interesse do fisco em que todas as manifestações de capacidade contributiva sejam efetivamente alcançadas.

No trabalho realizado, os setenta acórdãos do STF em que os termos "capacidade contributiva” aparecem foram classificados de acordo com o interesse protegido.

Estas análise e classificação conduzem a uma conclusão principal: no Brasil, o princípio da capacidade contributiva foi utilizado pelos ministros do STF, em alguns poucos acórdãos, para proteger o interesse do contribuinte e quase sempre para proteger o interesse do fisco.

Com efeito, no primeiro grupo, em que se tratou de proteger o interesse do contribuinte, o princípio da capacidade contributiva foi utilizado pelas partes, mas 
impostos terão caráter pessoal e serão graduados segundo a capacidade econômica do contribuinte [...]". ${ }^{2}$

Depois de publicada a constituição de 1946, a aplicação deste princípio foi objeto de discussão e divergência entre juristas, principalmente com relação a sua eficácia técnica. Na primeira edição de seu livro Teoria Geral do Direito Tributário, de 1963, Alfredo Augusto Becker mostra como duas correntes opunham-se com relação a esse ponto. ${ }^{3}$

Mesmo que alguns defendessem que o princípio da capacidade contributiva deveria produzir efeitos imediatamente, prevaleceu o posicionamento segundo o qual se trataria de regra meramente programática. Becker aponta, em seu livro, uma série de autores que seguiriam esse posicionamento. ${ }^{4}$

Reconduzido à condição de princípio constitucional pela constituição de 1988 e, passados vinte anos de sua promulgação, trata-se de saber se essa interpretação inicial se confirmou e de examinar a aplicação da norma em questão. O princípio da capacidade contributiva foi efetivamente interpretado pelo STF como uma norma meramente programática ou como uma norma que produziu efeitos imediatamente? No segundo caso, que direitos e obrigações estariam sendo efetivamente protegidos pelo princípio?

Para responder a essas perguntas, foi realizada uma pesquisa de jurisprudência no site do Supremo Tribunal Federal, cujos resultados são apresentados neste trabalho. Procurou-se verificar quantas vezes e em que situações o termo "capacidade contributiva” foi empregado, além de analisá-las e classificá-las de acordo com critérios apresentados mais à frente.

A utilização das palavras-chave “capacidade contributiva” resultou em setenta ocorrências até o mês de novembro de 2008. Em um caso, isto é, no RE 212.209/RS, ocorreu que, ainda que esse acordão não tenha aparecido quando da pesquisa com as palavras-chave referidas, o princípio da capacidade contributiva foi nele utilizado. Isso se deve ao fato de ter sido utilizada no referido acórdão a expressão "capacidade econômica do contribuinte”, e não capacidade contributiva. Esse acordão foi incluído na pesquisa que totalizou, portanto, 71 ocorrências.

\section{CONSIDERAÇÕES SOBRE A CLASSIFICAÇÃO}

Antes de explicitar o critério utilizado para classificar as decisões, serão feitas algumas observações preliminares com relação às decisões pesquisadas.

Em primeiro lugar, entre os 71 acordãos há oito tipos de medida judicial diferente: Recurso Extraordinário (RE); Agravo Regimental no Recurso Extraordinário (REAgR); Embargos de Declaração no Recurso Extraordinário (RE-ED); Agravo Regimental em Agravo de Instrumento (RE-AgR-AI); Embargos de Declaração em Agravo Regimental de Agravo de Instrumento (AI-AgR-ED); Ação Direta de Inconstitucionalidade (ADI); Medida Cautelar em Ação Direta de Inconstitucionalidade (ADI-MC); e Medida Cautelar em Ação Cautelar (AC-MC). Ao longo do trabalho, 
quando nos referimos a cada uma das medidas judiciais, foi utilizada a sigla que aparece depois de cada medida judicial específica. Esse critério formal, no entanto, não foi utilizado para efeito de classificação.

Além disso, é importante ressaltar que, nas 71 ocorrências da pesquisa jurisprudencial no site do STF, os termos "capacidade contributiva" aparecem em situações diferentes: muitas vezes, no voto de algum dos ministros e, outras vezes, ainda, no relatório, mas, em muitas ocasiões, o princípio aparece apenas no indexador do próprio tribunal, que se segue à ementa, ou na bibliografia indicada, não aparecendo no corpo do acórdão.

Por exemplo, na ADI/MC 1075/DF, em que se atribui caráter confiscatório à multa prevista no artigo $3^{\circ}$ da Lei 8.864/94 estabelecida em 300\% sobre o valor da operação ou do serviço prestado, sustenta-se violação ao princípio do não confisco. Nas referências bibliográficas do acordão, no entanto, aparece o livro de Regina Helena Costa (Princípio da Capacidade Contributiva). ${ }^{5} \mathrm{~A}$ mesma referência bibliográfica aparece na ADI-MC-QO 2551/MG sem que o princípio tenha sido utilizado no acórdão e, também, na ADC-MC 8, ao lado do livro de Elizabeth Nazar Carrazza (IPTU e Progressividade: igualdade e capacidade contributiva). ${ }^{6}$

Também no AI-AgR 360.461/MG, em que se sustenta que a isenção fiscal de IPI sobre a cana de açúcar concedida apenas às empresas situadas em uma determinada localidade geográfica violaria os princípios da seletividade, uniformidade e isonomia, previstos na constituição, decidiu-se que a isenção pode ter caráter extrafiscal com o objetivo de promover o desenvolvimento e superar as desigualdades sociais e regionais, não havendo, portanto, violação a nenhum dos dispositivos constitucionais referidos. No voto do ministro Celso de Mello, aparece a seguinte referência, depois reproduzida nas referências bibliográficas do acordão: "PONTES, Helenilson Cunha. O princípio da capacidade contributiva e extra-fiscalidade: uma conciliação possível e necessária. In: Ordem Econômica e Social. P 144-159".

Esses não são casos de aplicação efetiva do princípio da capacidade contributiva. Portanto, ocorrências como esta não foram objeto de classificação, pois se considerou que a utilização do princípio era apenas aparente. Portanto, excluídos os casos em que a aplicação do princípio da capacidade contributiva foi aparente, foram encontrados 67 acordãos.

Em outros casos, ainda que tenha sido arguida, seja pelo contribuinte, seja pelo fisco, suposta violação ao princípio da capacidade contributiva, o STF não se pronunciou sobre o tema. Normalmente, isso ocorreu devido à falta de prequestionamento. Este é, por exemplo, o caso do RE 284.619/PA, interposto contra acórdão que assegurou ao contribuinte o direito de não aplicar, na atualização monetária das demonstrações financeiras relativas ao ano-base de 1990, o BTN fiscal desvinculado do IPC, na forma prevista pela MP n ${ }^{\circ}$ 189/90, depois convertida na Lei n. 8.088/90. Em casos como esse, procurou-se, sempre que possível, 
classificar o acórdão. Com efeito, por um lado, está sendo argumentado que houve violação ao princípio da capacidade contributiva. Portanto, a referência ao princípio efetivamente ocorreu, o que é muito diferente de, na bibliografia referida no acórdão, existir um livro com a expressão "capacidade contributiva”.

Por outro lado, a referência é feita por uma das partes, isto é, pelos contribuintes. Os ministros, ao contrário, em sua maioria, rejeitam a aplicação do princípio. Por isso, os acórdãos em que isso ocorre foram classificados em um grupo autônomo, composto de acórdãos em que o princípio da capacidade contributiva foi utilizado não pelos ministros do STF, mas pelos contribuintes.

Tendo em vista essas considerações preliminares, na classificação das decisões, partiu-se dos trabalhos da doutrina italiana e, em especial, de Pietro Boria, segundo quem o princípio da capacidade contributiva desempenha uma função de proteção dos interesses tanto do fisco como do contribuinte.

Dada a semelhança entre o referido princípio nos dois países e a forte influência que o direito tributário brasileiro recebeu do direito tributário italiano, inclusive com relação à fundamentação teórica do princípio da capacidade contributiva, acreditamos que esse critério seja bastante esclarecedor no que diz respeito à doutrina e jurisprudência brasileiras. Ele será explicitado em seguida.

\section{INTERESSE DO FISCO E INTERESSE DO CONTRIBUINTE}

Segundo Pietro Boria, até o advento da modernidade, o direito tributário caracterizava-se por uma situação de "domínio fiscal" por parte do senhor absoluto. ${ }^{7} \mathrm{~A}$ partir do final do século 17, essa situação passa a mudar: começa a se desenhar um "interesse fiscal” na arrecadação de tributos. O Estado precisa de dinheiro para satisfazer as despesas públicas e esse interesse não é algo arbitrário, mas plenamente justificado.

Também nesse período começaram a se reconhecer interesses individuais, concorrentes ou até mesmo contrários ao interesse da coletividade na cobrança de tributos, que também passaram a merecer proteção. Os princípios tributários da legalidade, da anterioridade e da irretroatividade, por exemplo, são expressões da proteção desses direitos individuais que começaram a ser reconhecidas.

Assim, ao lado de um interesse do fisco, enquanto representante da comunidade, em arrecadar recursos para satisfazer as despesas públicas, afirma-se também um interesse dos cidadãos em terem sua esfera de propriedade e liberdade preservadas.

A consolidação desses dois interesses opostos, ambos a merecer proteção, dá as linhas gerais dos sistemas tributários contemporâneos e é a partir dessa estrutura que será analisado também o princípio da capacidade contributiva e sua aplicação.

$\mathrm{Na}$ Itália, depois de uma fase inicial na qual referido princípio foi concebido como norma meramente programática, ele passou a estar associado à proteção do interesse do contribuinte. ${ }^{8}$ 
Com efeito, tanto a doutrina como a jurisprudência desse país passaram a lhe atribuir um conteúdo preciso: força econômica. Dessa forma, apenas onde pudesse ser encontrada força econômica poderia haver, também, capacidade contributiva e, consequentemente, tributação. A consequência prática disso foi o reconhecimento de algumas situações, como a de uma zona de mínimo vital, que não poderiam ser tributadas por não revelarem capacidade contributiva.

A partir da década de 1970, no entanto, uma outra interpretação do princípio da capacidade contributiva começa a ganhar força na Itália. De acordo com essa interpretação, esse princípio estaria virtualmente ligado e deveria ser interpretado à luz do artigo $2^{\circ}$ da constituição italiana, que consagra o dever de solidariedade. ${ }^{9}$

Nesse sentido, o princípio da capacidade contributiva teria um papel fundamental na proteção do interesse do fisco: tendo em vista o ideal de solidariedade, o aspecto a ser destacado no princípio passa a ser o de que ninguém deveria se furtar a contribuir para as despesas públicas conforme sua capacidade contributiva. Dessa forma, se analisado detidamente o princípio, dois interesses distintos são tutelados: em primeiro lugar, o interesse do contribuinte, à medida que ninguém deve ser tributado para além de sua capacidade contributiva. Além dele, o interesse do fisco, pois todas as manifestações de capacidade contributiva não podem escapar à tributação. ${ }^{10}$

\section{Proteção do interesse do contribuinte}

$\mathrm{Na}$ análise da jurisprudência realizada, foi nosso objetivo verificar como o princípio da capacidade contributiva estava sendo utilizado no âmbito do STF e, em especial, qual desses dois interesses tratava-se de proteger.

Constatou-se que, nas discussões dos casos que foram objeto dos acórdãos, o princípio da capacidade contributiva foi utilizado na proteção de ambos os interesses e que esse critério mostrava-se elucidativo para classificá-los.

Depois de terem sido excluídos os acórdãos em que a utilização do princípio da capacidade contributiva era meramente aparente, eles foram divididos em cinco grupos. Nos dois primeiros grupos, tratou-se de proteger o interesse do contribuinte.

O primeiro grupo foi composto por acórdãos nos quais a violação ao princípio da capacidade contributiva é alegada pelo contribuinte, mas o argumento não é aceito ou pela unanimidade dos ministros, ou pela maioria vencedora. Portanto, ainda que não tivesse sido aceito pelos ministros, o princípio da capacidade contributiva foi utilizado pelos contribuintes na proteção de seu interesse. Esse grupo foi composto por 22 acordãos.

O segundo grupo foi composto por acórdãos em que o princípio da capacidade contributiva foi usado na defesa do interesse do contribuinte de duas formas diferentes. Ele é composto por 21 acórdãos.

Nesse grupo, um primeiro subgrupo trata de situações em que, apesar de o princípio da capacidade contributiva ter sido aplicado pelas instâncias inferiores, o STF 
decidiu pela sua não aplicação às situações em questão. Tratou-se, nesses casos, também de proteger o interesse do contribuinte, evitando uma tributação maior justamente por decidir-se que essas situações não deveriam ser tributadas de acordo com a capacidade contributiva. Esses acórdãos dizem respeito à progressividade do IPTU, do ITBI. Há também um acórdão tratando do IPVA.

Um segundo subgrupo é composto por três acórdãos em que o princípio da capacidade contributiva é utilizado, seja no voto vencedor, seja no voto vencido, expressamente na defesa do interesse do contribuinte contra o fisco.

No primeiro caso, decide-se que as movimentações financeiras não poderiam ser escolhidas para fato gerador da CPMF por não exprimirem nenhuma manifestação de capacidade contributiva. Essa argumentação foi utilizada em dois acórdãos.

No segundo caso, trata-se de acórdão em que se decide que violação ao princípio da não cumulatividade significaria igualmente violação ao princípio da capacidade contributiva.

No primeiro subgrupo, 15 acordãos tratam da progressividade do IPTU, instituída pelas leis municipais das cidades de Porto Alegre, Rio de Janeiro e Ipatinga; dois acórdãos tratam da progressividade do ITBI no município de São Paulo; e um último trata da progressividade do IPVA. Nos dois primeiros casos, trata-se de afastar a cobrança progressiva, pois a constituição não autorizaria que a cobrança fosse feita de acordo com a capacidade contributiva. No terceiro caso, trata-se de autorizar a cobrança progressiva quando não utilizada com base na capacidade contributiva.

Com relação à progressividade do IPTU, em todos os casos, a fundamentação é a mesma. A título de exemplo, examine-se o AI-AgR 438.366-6/RJ, em que o ministro Eros Grau foi relator. De acordo com o voto do relator:

[...] esta corte firmou entendimento no sentido de que a Prefeitura do Rio

de Janeiro lançava e cobrava IPTU levando em conta a área e a localização

dos imóveis, o que revelava a capacidade contributiva, modelo repelido pela

CF/88, que só admite a progressividade do IPTU para fins extra-fiscais. ${ }^{11}$

De acordo com os acórdãos, o texto da constituição de 1988, anterior à emenda 29/2000, comportava uma única progressividade: a progressividade extra-fiscal, prevista no artigo 182 da constituição. Por isso, trata-se, em todos os casos, de impedir a cobrança progressiva, feita com base na capacidade contributiva. ${ }^{12}$

Dois casos trataram da impossibilidade de cobrança do ITBI de forma progressiva: RE 227.033/SP e RE 234.105/SP. Ambos são recursos contra decisões de segunda instância que admitiram essa forma de cobrança. De acordo com os acórdãos, a lei do município, ao instituir a cobrança progressiva do ITBI, presumiu maior capacidade contributiva dos sujeitos passivos compradores de imóveis maiores, de modo a "conferir a um tributo real uma personalização ilegítima”. 
Nos termos de um dos acórdãos, na constituição, não há autorização expressa para cobrança do ITBI progressivo, pois, se o constituinte quisesse que a cobrança fosse progressiva, teria estabelecido expressamente.

Portanto, seja porque a constituição não autoriza expressamente cobrança progressiva do ITBI, seja porque não é possível presumir-se maior capacidade contributiva dos compradores de imóveis maiores, o STF afastou a cobrança progressiva. O princípio da capacidade contributiva foi aplicado, assim, na defesa do interesse do contribuinte contra o fisco.

\section{Proteção do interesse do fisco}

Os três grupos seguintes tratam de situações em que o princípio da capacidade contributiva não foi apenas arguido por uma das partes, mas efetivamente aplicado por um ou mais ministros. Em todas elas, a aplicação foi feita na defesa do interesse do fisco.

No terceiro grupo, foram incluídos sete acordãos em que o princípio da capacidade contributiva é utilizado, de forma geral, para proteger o interesse do fisco. Em todos esses casos, tratou-se de afastar o argumento do contribuinte, mostrando-se como, nas situações em questão, havia capacidade contributiva, devendo, portanto, haver tributação.

Exemplo desse uso do princípio é o RE 116.121/SP, em que se alega a inconstitucionalidade do item 79 da lista de serviços anexa ao Decreto 406/68, na redação dada pela lei complementar n. $56 / 87$ e do item $78, \S 3^{\circ}$ do artigo 50 da lista de serviços da Lei 3.750/71 do município de Santos.

O contribuinte sustenta que a locação de guindastes consiste em obrigação de dar, o que implicaria em violação ao artigo 110 do CTN, posto que, no direito privado, o conceito de serviço é o de obrigação de fazer.

Deu-se provimento ao recurso para declarar-se a inconstitucionalidade dos dispositivos apontados. Em seu voto vencido, porém, o ministro Nelson Jobim reportou-se ao RE 112.947/SP, de 07.08.1987, em que foi relator o ministro Carlos Madeira, assim redigido: "na locação de guindastes, o que tem relevo é a atividade com eles desenvolvida, que adquire consistência econômica, de modo a tornar-se um índice de capacidade contributiva do Imposto sobre serviços". Portanto, o argumento utilizado no voto vencido é o de que, na atividade de locação de guindastes, há manifestação de capacidade contributiva e, assim, deveria haver tributação.

No quarto grupo, foram incluídos outros sete acórdãos que tratam da aplicação do princípio da capacidade contributiva no interesse do fisco, mas em uma situação bastante específica, qual seja, às taxas.

Com efeito, nos termos do artigo 145, $\S 1^{\circ}$, da Constituição de 1988, literalmente, o princípio da capacidade contributiva se aplicaria apenas a uma das cinco 
espécies de tributo, qual seja, aos impostos: "Sempre que possível, os impostos [...]" (art. $145, \S 1^{\circ}$ ).

No quarto grupo, foram incluídos os acórdãos que procuram aplicar o princípio da capacidade contributiva a uma outra espécie tributária: as taxas. Mesmo que literalmente a constituição disponha que o princípio aplica-se aos impostos, o STF entendeu que nada impede que seja aplicado também às taxas. Nesse sentido, por exemplo, a ADI 453/DF, em que foi relator o ministro Gilmar Mendes. A Lei 7.940, que considerou os auditores independentes como contribuintes da taxa de fiscalização do mercado de títulos e valores mobiliários, estabeleceu valores diferentes e específicos para cada faixa de contribuintes.

Alegou-se que isso violaria o princípio da isonomia. Em seu voto, justificando a cobrança diferenciada, o Min. Carlos Velloso escreveu que a cobrança diferenciada procurava justamente atender ao princípio da capacidade contributiva.

Também sobre a possibilidade de outras taxas serem estabelecidas com base em valores diferentes, a ADI-MC 1948/RS, que julgou a alegação de inconstitucionalidade da cobrança da taxa de serviços diversos em favor da Agência Estadual de Regulação dos Serviços Públicos Delegados do Rio Grande do Sul, e a ADI $3151 /$ MT, que julgou a suposta inconstitucionalidade do artigo $8^{\circ}$ da Lei $8.033 / 2003$, que, para disciplinar a cobrança dos recursos do fundo de apoio ao judiciário - Funajuris -, dispôs que seriam criadas três categorias de serviços notariais: serventias pequenas e deficitárias, serventias médias e serventias grandes. Seu parágrafo único dispôs que a cobrança seria progressiva.

No quinto grupo, por sua vez, foram incluídos dez acórdãos ou grupos de acórdãos semelhantes. Trata-se também da aplicação do princípio da capacidade contributiva na defesa do interesse do fisco. Em todos os casos, no entanto, as situações se assemelham.

Trata-se sempre, nesses acordãos, de casos em que se dispensava um tratamento diferenciado a algumas situações que se apresentavam distintas. O contribuinte sempre se insurgia contra a diferenciação, alegando principalmente violação ao princípio da isonomia. O princípio da capacidade contributiva foi utilizado, em todos os acórdãos, como forma de assegurar tratamento diferenciado às situações distintas.

Exemplo desse tipo de aplicação encontra-se no AI - Ag Rg 452.642/MG, em que foi relator o ministro Carlos Velloso. Alegou-se que o artigo $9^{\circ}$ da Lei 9.317/96, ao impossibilitar as pessoas jurídicas prestadoras de serviço optarem pelo Simples, estaria instituindo tratamento desigual entre contribuintes em situação equivalente, violando, supostamente, o artigo 150, II, da Constituição Federal.

Decidiu-se que não há ofensa ao princípio da isonomia se a lei, por motivos extra-fiscais, imprime tratamento desigual a microempresas e empresas de pequeno porte de capacidade contributiva distinta. Portanto, o princípio da capacidade contributiva estaria sendo utilizado na proteção do interesse do fisco, justamente para justificar o tratamento diferenciado. 
sua utilização não foi aceita pelos ministros do STF. Em alguns poucos casos, ele é aceito por um ministro que teria sido voto vencido.

Por outro lado, no segundo grupo, em que se tratou também de proteger o interesse do contribuinte, isso foi feito justamente com a decisão de não aplicar, aos casos em questão, o princípio da capacidade contributiva.

Algumas poucas exceções em que o princípio foi efetivamente aplicado na defesa do interesse do contribuinte podem ser encontradas nos votos vencidos do ministro Ilmar Galvão, segundo o qual não se justifica um tributo sobre movimentações financeiras, por elas não exprimirem nenhuma manifestação de capacidade contributiva, e no voto vencido do ministro Marco Aurelio, de acordo com o qual a inclusão do tributo, somado ao preço para determinação da base de cálculo do ICMS, violaria o princípio da capacidade contributiva.

$\mathrm{Na}$ grande maioria das vezes em que foi utilizado pelos ministros do STF, no entanto, o princípio da capacidade contributiva foi utilizado na defesa do interesse do fisco e os três últimos grupos mostram as aplicações que vêm sendo feitas do referido princípio pelo Supremo Tribunal Federal.

Seja para assegurar a tributação diferenciada em algumas situações, como no caso de empresas optantes pelo Simples, seja para garantir que as taxas possam ser cobradas com alíquotas diferenciadas, seja, de maneira geral, para assegurar a tributação nas situações em que exista manifestação de capacidade contributiva, o princípio da capacidade contributiva foi utilizado sempre de modo a que, nas situações em que se revele capacidade contributiva, a tributação não deixe de alcançá-la.

: ARTIGO APROVADO (23/06/2009) : RECEBIDO EM 08/12/2008

\section{NOTAS}

1 Doutor em Direito pela USP. Foi pesquisador visitante na New School for Social Research (Nova York, EUA) e na Università Commerciale Luigi Bocconi (Milão, Itália). Professor do programa de pós-gradução em administração de empresas (PPGA) da Universidade Nove de Julho (Uninove).

2 Victor Uckmar aponta uma série de constituições recentes que prevêem a distribuição dos impostos com base "nas possibilidades econômicas" dos contribuintes. Argentina (1946) "art. 28 - A eqüidade e a proporcionalidade estão na base dos impostos e dos gastos públicos"; Bolívia (1967) "art. 8, 'd' - contribuir em proporção a sua capacidade econômica para a sustentação dos serviços públicos”; Bulgária (1947) "art. 94 - Os encargos fiscais são subdivididos entre todos os cidadãos proporcionalmente às suas capacidades econômicas”; Equador (1966/1967) - 
“art. 182 - Os impostos devem ser estabelecidos em proporção à capacidade econômica do contribuinte"; Grécia (1951) - "art. 3 - Os cidadãos gregos contribuem sem distinção aos encargos públicos, em proporção às suas possibilidades"; México (1917) - "art. 31 - Os mexicanos são obrigados: [...] IV - a contribuir para as despesas públicas seja da Federação, seja do Estado e do Município onde residam em medida proporcional e equânime que será fixada pela lei”; Suíça (1981) - “Art. 41 - As pessoas jurídicas, qualquer que seja a sua forma, devem ser tributadas de acordo com a sua capacidade econômica e de modo tanto quanto for possível igual”. Outras constituições além da referência às possibilidades econômicas fazem referência à progressividade: Chile (1925) "art. 10 - A constituição garante a todos os habitantes da República: (... 9) a igual repartição dos impostos e taxas, em proporção à riqueza, ou segundo a progressividade fixada pela lei, e a igual repartição dos outros encargos públicos”; Jordânia (1952) “art. 111 - o Governo, ao impor taxas, deve ater-se ao princípio de uma taxação progressiva respeitando a igualdade e a justiça social e não deve ultrapassar a capacidade de os sujeitos passivos pagarem e a necessidade de dinheiro do Estado"; Itália (1947) “art. 53 - Todos devem concorrer para as despesas públicas em função da sua capacidade contributiva. O sistema tributário é informado por critérios da progressividade"; Síria (1950) "art. 25 - as taxas são impostas mediante bases justas e progressivas que assegurem os princípios de igualdade e justiça social”; Espanha (1977) "art. 31.1 - Todos contribuirão à cobertura das despesas públicas em função da sua capacidade econômica mediante um sistema inspirado os princípios da igualdade e progressividade que, em nenhum caso, terá efeitos confiscatórios”; Venezuela (1947) “art. 282 - O regime nacional das entradas será organizado e funcionará sobre bases de justiça e igualdade tributária com o fito de atuar uma repartição de impostos e contribuições progressiva e proporcional à capacidade econômica do contribuinte, a elevação do nível de vida e o poder aquisitivo dos consumidores e a proteção bem como o incremento da produção nacional". (UCKMAR, Victor. Princípios comuns de direito constitucional tributário. 2. ed. São Paulo: Malheiros, 1999, p. 80-81).

3 BECKER, Alfredo Augusto. Teoria Geral do Direito Tributário. São Paulo: Saraiva, 1963, p. 441. Becker refere-se à constitucionalização do princípio da capacidade contributiva de "constitucionalização do equívoco".

4 BECKER, Alfredo Augusto. Teoria Geral do Direito Tributário. São Paulo: Saraiva, 1963, p. 444.

5 Princípio da Capacidade Contributiva. São Paulo: Malheiros, 2003.

6 IPTU e Progressividade: igualdade e capacidade contributiva. Curitiba: Juruá, 1992.

7 BORIA, Pietro. L'Interesse Fiscale. Torino: Giappichelli, 2002, p. 12 e seguintes. Desenvolvi de maneira mais detida esse tema em Pessôa, Leonel Cesarino. "Interesse fiscal, interesse dos contribuintes e o princípio da capacidade contributiva”. In: Direito Tributário Atual, vol 18, IBDT/Dialética, 2004.

8 Cf. a esse respeito, os seguintes livros: GAFFURI, Franco. L'atitudine alla Contribuzione. Milano, Giuffrè, 1965. GIARDINA, Emilio. Le Basi Teoriche del Principio della Capacità Contributiva. Milano, Giuffrè, 1961.

9 Cf., a esse respeito: MOCHETTI, Francesco. Il Principio della Capacità Contributiva. Padova, Cedam, 1973 e MARONGIU, Gianni. "Il Principio di Capacità Contributiva nella Giurisprudenza della Corte Costituzionale" In: Diritto e Pratica Tributaria 1985, I.

10 Desenvolvi detidamente esse tema em: PESSÔA, Leonel Cesarino. "Interesse fiscal, interesse do contribuinte e o princípio da capacidade contributiva”. In: Direito Tributário Atual, n 18, IBDT/Dialética, 2004.

11 AI-AgR 438.366-6/RJ.

12 Analisei o posicionamento do Supremo Tribunal Federal, criticando sua decisão no artigo: PESSÔA, Leonel Cesarino. "IPTU, Impostos Reais e Progressividade”. In: Revista Tributária e de Finanças Públicas, n 60, jan/fev 2005 Sobre esse tema, ver também: CONTI, José Maurício. Princípios Tributários da Capacidade Contributiva e da Progressividade. São Paulo, Dialética, 1997; ZILVETI, Fernando. Princípio de Direito Tributário e a Capacidade Contributiva. São Paulo, Quartier Latin, 2004; ATALIBA, Geraldo. "IPTU - Progressividade” in: Revista de Direito Público n. 93, pgs. 233-238; COSTA, Alcides Jorge. "IPTU - Progressividade" in: Revista de Direito Público n. 93. 
106 : O PRINCÍPIO DA CAPACIDADE CONTRIBUTIVA NA JURISPRUDÊNCIA DO SUPREMO TRIBUNAL FEDERAL

\section{REFERÊNCIAS BIBLIOGRÁFICAS}

ATALIBA, Geraldo. "IPTU - Progressividade" in: Revista de Direito Público n. 93, pgs. 233-238.

BECKER, Alfredo Augusto. Teoria Geral do Direito Tributário. São Paulo: Saraiva, 1963.

BORIA, Pietro. L'interesse Fiscale. Torino, Giappichelli, 2002.

"Commento all'art. 53 Cost". A ser publicado In: Diritto e Pratica Tributaria 4, 2004.

CARRAZZA, Roque Antonio. Curso de Direito Constitucional Tributário. 14 a edição, São Paulo, Malheiros, 2000.

CARRAZZA, Elizabeth Nazar. Progressividade e IPTU. Curitiba, Jaruá, 1992.

CARVAlHO, Paulo de Barros. Curso de Direito Tributário. 13 $3^{\mathrm{a}}$ edição, São Paulo, Saraiva, 2000.

CONTI, José Maurício. Princípios Tributários da Capacidade Contributiva e da Progressividade. São Paulo, Dialética, 1997.

COSTA, Alcides Jorge. "IPTU - Progressividade” in: Revista de Direito Público n. 93, pgs. 239-242.

DE MITA, Enrico. Fisco e Costituzione II. Milano, Giuffré, 1993.

DE VITI DE MARCO, Antonio. Principii di Economia Finanziaria. Torino, Einaudi, 1934.

EINAUDI, Luigi. Principii di Scienza della Finanza. Torino, La Riforma Sociale, 1932.

GAFFURI, Franco. L'atitudine alla Contribuzione. Milano, Giuffrè, 1965.

GIARDINA, Emilio. Le Basi Teoriche del Principio della Capacità Contributiva. Milano, Giuffrè, 1961.

MARONGIU, Gianni. "Il Principio di Capacità Contributiva nella Giurisprudenza della Corte Costituzionale" In: Diritto e Pratica Tributaria 1985, I, pgs. 6-28.

. "La Crisi Del Principio di Capacità Contributiva nella Giurisprudenza della Corte Costituzionale

dell'Ultimo Decenio”. In: Diritto e Pratica Tributaria, vol LXX, 1999.

MOCHeTTI, Francesco. Il Principio della Capacità Contributiva. Padova, Cedam, 1973. (a cura di). La Capacità Contributiva. Padova, Cedam, 1993.

PESSÔA, Leonel Cesarino. "Interesse fiscal, interesse do contribuinte e o princípio da capacidade contributiva". In: Direito Tributário Atual, nº 18, IBDT/Dialética, 2004.

jan/fev 2005 "IPTU, Impostos Reais e Progressividade". In: Revista Tributária e de Finanças Públicas, nº 60

UCKMAR, Victor. Princípios comuns de direito constitucional tributário. $2^{\text {a }}$ edição. São Paulo: Malheiros, 1999.

ZILVETI, Fernando. Princípio de Direito Tributário e a Capacidade Contributiva. São Paulo, Quartier Latin, 2004.

\section{Leonel Cesarino Pessôa}

Rua Minas Gerais, 186 Higienópolis - 01244-010 São Paulo - SP - Brasil ces.pessoalauol.com.br
DOUTOR EM DIREITO PELA USP. PROFESSOR DO PROGRAMA DE PÓS-GRADUACÃO EM ADMINISTRAÇÃO DE EMPRESAS (PPGA) da Universidade Nove de Julho (Uninove) 